\title{
Experimental and Simulation Investigation of Bending Moment Effect on Hollow Columns of Multi-layers of Hybrid Materials
}

\author{
Ayad A. Ramadhan \\ Department of Mechanical Engineering, Al-Hawija Technical Institute, Northern Technical University \\ ayad_almuhndis@yahoo.com
}

\begin{abstract}
This paper presented the effect of bending on multi-layer of hollow columns of Hybrid materials (Carbon-Glass lepoxy-Alumina) composite this effect occurred and volume fraction of fibers. An experimental procedure was developed to study the performance of these effects under bending load using a hydraulic bending device type (MATEST. SRL) testing machine. This study has three forms through the selection of columns hollows width to thickness (a/b) $(0.5,1$ and 2$)$ with three types of layers of samples $(2,4$ and 8$)$ layers. The ultimate load of failure for each Hybrid/epoxy- $\mathrm{Al}_{2} \mathrm{O}_{3}$ had been determined and specified the optimum volume fraction $\left(\mathrm{V}_{\mathrm{f}}\right)$ due to the effect of mixing $50 \%$ and $60 \%$ were low in the case for compared $55 \%$ volume fraction. To simulate this problem the researcher used Explicit Mesh for AUTODYN under ANSYS-15 software, it was found that maximum bending load for Hybrid/ Epoxy$\mathrm{Al}_{2} \mathrm{O}_{3}$ Specimens, the maximum load of specimens increased with increasing number of layers from $2 \mathrm{~L}$ to $8 \mathrm{~L}$. The results also identified that the maximum load capacity by $55 \%$ volume fraction and $\mathrm{a} / \mathrm{b}=0.5$ of all composite specimens was highest from the others types of $(50 \%$ and $60 \%)$ volume fractions and $(\mathrm{a} / \mathrm{b}=1$ and $\mathrm{a} / \mathrm{b}=2)$ .Also, the Increasing ratio of stress capacity for specimens have 4 to 2 layers (4/2) and 8 to 4 (8/4) for experimental results have maximum value with increasing by $48.19 \%$ and $46.84 \%$ at (Sp.4\#8/Sp.2\#4) and (Sp.8\#6/Sp.4\#6) respectively.
\end{abstract}

Keywords: Experimental study; Simulation study; AUTODYN; Bending load; Hybrid materials; and Hollow columns.

\section{Paper History:}

(Received: 24/4/2017; Accepted: 22/11/2017)

\section{Introduction}

A composite material is made by combining two or more dissimilar materials. They are combined in such a way that the resulting composite material or composite possesses superior properties which are not obtainable with a single constituent material. So, in technical terms, we can define a composite as 'a multiphase material from a combination of materials, differing in composition or form, which remain bonded together, but retain their identities and properties, without going into any chemical reactions.' The components do not dissolve or completely merge. They maintain an interface between each other and in concert to provide improved, specific or synergistic characteristics not obtainable by any of the original components acting singly[1-3]. Thin cylinders of fiber-reinforced plastic (FRP) material are used in large quantities as a kind of structural material for robot arms, airplanes and aerospace applications because of their light weight and high strength. Limin Bao and Natsuki Kamada [et al] [4] improved the mechanical properties of these cylinders, this study applied the VaRTM method to develop a biomimetic design of a thin cylinder with nodes that imitate a bamboo structure. They studied effects of inserted nodes on the bending properties of a thin FRP cylinder that were examined by the fourpoint bending test. It is evident that the flexural rigidity and bending buckling load were increased; the validity of the node has also been confirmed. Several researchers found that bending strength was greater than tensile strength in polymeric composite materials[5-8]. Liu [9] tested the bending fatigue lifetime of the aramid fiber by using a sample bending fatigue apparatus and $\mathrm{Gu}[10]$ investigated the bending fatigue strength of the wool fiber. Burgoyne and Hobbs [11] used a sheave bending apparatus to investigate the bending fatigue of parallel lay aramid ropes. Todd.[12] got numbers of cyclesto strength degradation curves under a low tension, which proved that the bending fatigue damage of the aramid fibers used for communication cables are small under the low tension. Kohji [et al] [13]. The pultruded polymer matrix composite sections are being increasingly used in structural applications such as bridge decks, panels, railings, gratings, and standard sections (circular, square, rectangular, wide flange, I, channel, etc.). Based on geometry, the composite members can be classified as thin-walled members, and the glass 
fiber orientation results in orthotropic material behavior. The behavior of fiber-reinforced composites has been typically explained in the light of Micromechanics and Classical Laminate Theory (CLT), as reported by many researchers, [14-20] wherein the laminate properties of composites are given. During field applications, the pultruded members are subject to different types of loads, including combined torsion and bending, potentially resulting in structural instability, including various modes of buckling. Response of closed Glass Fiber Reinforced Polymer sections under combined bending and torsion was studied by Muhammad AM Qureshi [et al] [21]. Phan and Reddy [22]. applied this theory for the bending, the free vibration, and the buckling of composite plates. Idlbi [et al.] [23]. compared trigonometric or sine functions shear deformable plate theory TSDPT and parabolic shear deformable plate theories PSDPT for the bending of cross-ply plates. Recently, Karama [et al] [24]. proposed an exponential variation for the transverse strain in their investigation of the bending of composite beams. A comprehensive literature review revealed that most of the experimental work done on pultruded composite materials is limited to flexural loading or compressive axial loading (no load interaction) at component level, but mainly at coupons level. However, research on torsional loading of pultruded members is limited, and certainly no prior research work has been reported on testing full-size specimens till failure under combined bending and torsion. Testing full-size specimens can be a challenge because of absence of standard test methodologies. While theories of isotropic material response have also been modified for composite materials and reported in literature, [25 The theory of anisotropic plates also helps define the behavior of fiber-reinforced composites 29] The design manuals of structural members of various cross-sectional shapes have been developed by professional societies and manufacturers.[30-32] Moreover, finite element analysis (FEA) of GFRP composite members was performed here in to compare the response data under complex loading conditions with our experimental data. The bending fatigue behaviors were investigated in glass fiberreinforced polyester composite plates, made from woven-roving with four different weights., $800,500,300$, and $200 \mathrm{~g} / \mathrm{m} 2$, random distributed glass-mat with two different weights 225 , and $450 \mathrm{~g} / \mathrm{m} 2$ and polyester resin [33]. Portal axle shaft analyzed by Finite Element Analysis considered three different composite materials and varying parameters. i.e rib thickness and hollow shaft thickness are considered. Some of the parameters are kept constant, they are depth of spokes, rib fillet radius, number of spokes.
Torsional strength of the shaft compared for three different materials. When thickness are varied Deformation and Stresses are almost same for Kevlar/Epoxy and Boron/Epoxy materials but varied for E-Glass/Polyester Resin. Similarly When Shaft Thickness is varied the results are same for Kevlar/Epoxy and Boron/Epoxy but varied for E-Glass/Polyester Resin material. the effect of stacking sequence on mechanical properties of untreated luffa cylinder and glass fiber reinforced epoxy hybrid composites has been investigated experimentally by Niharika Mohanta \& Acharya [35]. the mechanical properties of three types of composite materials using natural rubber vulcanized, un vulcanized and reinforced rubber have been investigated by Dr. Hani Aziz Ameen.[36] in this study the bending properties of a glass polyester hollow shaft had been studied.

In this work, the experimental study of bending load effect on hollow columns that are mad from hybrid (Carbon-Glass) fiber with epoxy- $\mathrm{Al}_{2} \mathrm{O}_{3}$ with different $(2,4$ and 8$)$ number of layers has been studied with two shapes of cross-sectional area of specimen (rectangular and square shape). The effect of bending load different type of volume fraction $(50 \%, 55 \%$ and $60 \%$ ) with different number of layers on the strength of columns is studied via both experimental and simulation approaches by using ANSYS V.15. Experimental investigation of strength in Hybrid materials subjected to bending load is performed by using MATEST S.R.L TREVOLO 0824048 ITALY bending device. A comparison between test results is made to demonstrate the suitability of the composite materials in maximum stress capacity.

\section{Methodology and Materials Selection 2.1. Materials selection and specimen fabrication}

Two kinds of fiber (Carbon and Glass) with $\left(0^{\circ} / 90^{\circ}\right)$ fiber orientations for hollow columns of Hybrid materials (Carbon-Glass/epoxy-Alumina) had been selected to fabricate the composite materials as follow:-

1- Woven fiber Carbon

2- Woven fiber Glass

3- Epoxy + Hardener

4- Alumina $\left(\mathrm{Al}_{2} \mathrm{O}_{3}\right)$ powder.

The mechanical properties of these materials have been specified in Table 1 as bellow The volume fraction of fiber $\mathrm{V}_{\mathrm{f}}$ (fiber volume/total volume) in composites is very often significantly less than $100 \%$, and it was tested by (Hyer, 1998), so the volume fraction was selected by $55 \%$ in this work, it was an optimum value 
compared with others volume fraction for fabricating the specimens.

Table 1 Properties of materials used.

\begin{tabular}{|c|c|c|c|}
\hline \multirow{2}{*}{ Properties } & \multicolumn{3}{c|}{ Material type } \\
\cline { 2 - 4 } & Carbon & Glass & Alumina \\
\hline Diameter $(\mu \mathrm{m})$ & $8-9$ & - & \\
\hline Density $\left(\mathrm{Kg} / \mathrm{m}^{3}\right)$ & $\begin{array}{c}1780- \\
1820\end{array}$ & 2490 & 3.71 \\
\hline Tensile Modulus $(\mathrm{GPa})$ & $\begin{array}{c}228- \\
276\end{array}$ & 68.9 & \\
\hline Tensile Strength $(\mathrm{MPa})$ & $\begin{array}{c}2410- \\
2930\end{array}$ & 3160 & \\
\hline Elongation $(\%)$ & 1.0 & 4.8 & \\
\hline Thermal Expansion Coefficient $\left(\times 10-6 /{ }^{\circ} \mathrm{C}\right)$ & - & 7.2 & 5.4 \\
\hline Thermal Conductivity $\left(\mathrm{W} / \mathrm{m} /{ }^{\circ} \mathrm{C}\right)$ & 20 & - & $30-40$ \\
\hline Specific Heat $\left(\mathrm{J} / \mathrm{kg} /{ }^{\circ} \mathrm{K}\right)$ & 950 & 780 & \\
\hline
\end{tabular}

Three shapes of hollow columns; wide to height ratio $(\mathrm{a} / \mathrm{b}=0.5,1$ and 2$)$ with three types of samples (2,4 and8) layers. All the specimens have the same length which is $320 \mathrm{~mm}$, but the active length $280 \mathrm{~mm}$ will carry the bending load of the test until failure occurs by bulking the specimen as shown in Figure 1, while failure at mid of the hybrid specimen generated by the bending test (simply supported beam) would lead to maxi mum deformation in the center of the specimen. The maximum load and stress of failure for each of the Hybrid/epoxy- $\mathrm{Al}_{2} \mathrm{O}_{3}$ under bending has been determined. The lower horizontal edges of the plate are loaded at a midpoint of specimen. In all cases, the hollow columns boundary is a simply supported beam as well.

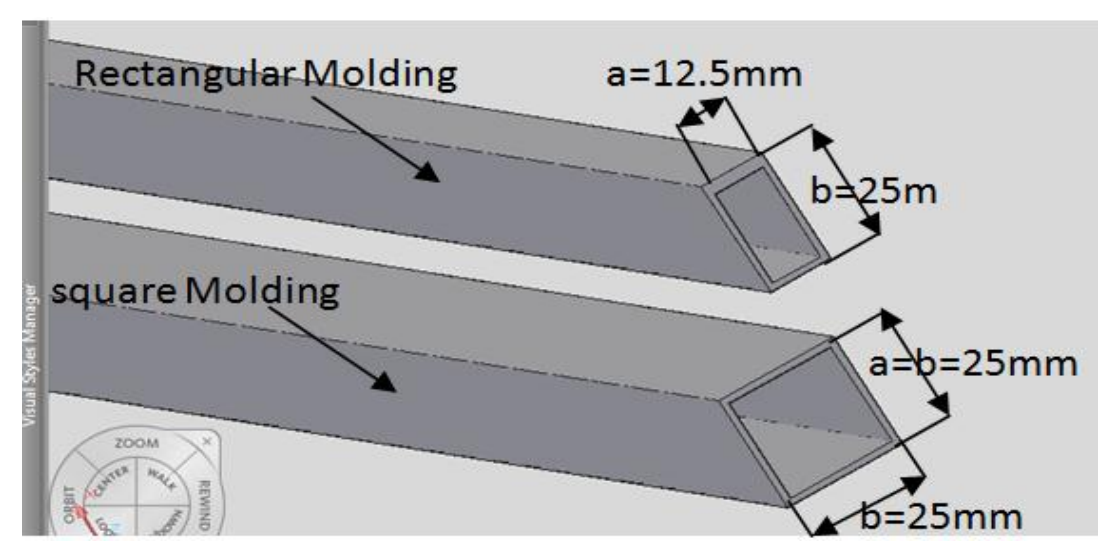

Figure 1: Rectangular and Square shape of specimen drawn by AUTOCAD Program

The specimens specified in the number of layers and volume fraction $\left(\mathrm{V}_{\mathrm{f}}\right)$ with $\left(0^{\circ} / 90^{\circ}\right)$ fiber orientation angle as listed in Table 2. The volume fraction of the woven fiber affects the behavior of orthotropic specimens under an applied bending load. Three types of layers of samples (2, 4 and 8) layers with different $(50 \%$, $55 \%$ and $60 \%$ ) volume fraction $\mathrm{V}_{\mathrm{f}}$ has been fabricated in this work. That it is need to paint the fiber textured Epoxy plus the amount of hardener $1.5 \%$ of the required amount of Alumina powder.

Table 2 Specimen fabricated of hybrid composite (27 specimens).

\begin{tabular}{|c|c|c|c|c|c|c|c|c|}
\hline $\begin{array}{c}\text { Specimen } \\
\text { of } \\
\text { (2Layers) }\end{array}$ & $V_{f}$ & $\begin{array}{c}\text { Width } \\
\text { /High } \\
\text { Ratio } \\
\text { (a/b) }\end{array}$ & $\begin{array}{c}\text { Specimen } \\
\text { of } \\
\text { (4Layers) }\end{array}$ & $V_{f}$ & $\begin{array}{c}\text { Width } \\
\text { /High } \\
\text { Ratio } \\
\text { (a/b) }\end{array}$ & $\begin{array}{c}\text { Specimen } \\
\text { of } \\
\text { (8Layers) }\end{array}$ & $V_{f}$ & $\begin{array}{c}\text { Width } \\
\text { VHigh } \\
\text { Ratio } \\
\text { (a/b) }\end{array}$ \\
\hline Sp.2\#1 & $50 \%$ & 0.5 & Sp.4\#1 & $50 \%$ & 0.5 & Sp.8\#1 & $50 \%$ & 0.5 \\
\hline Sp.2\#2 & $55 \%$ & 0.5 & Sp.4\#2 & $55 \%$ & 0.5 & Sp.8\#2 & $55 \%$ & 0.5 \\
\hline Sp.2\#3 & $60 \%$ & 0.5 & Sp.4\#3 & $60 \%$ & 0.5 & Sp.8\#3 & $60 \%$ & 0.5 \\
\hline Sp.2\#4 & $50 \%$ & 1 & Sp.4\#4 & $50 \%$ & 1 & Sp.8\#4 & $50 \%$ & 1 \\
\hline Sp.2\#5 & $55 \%$ & 1 & Sp.4\#5 & $55 \%$ & 1 & Sp.8\#5 & $55 \%$ & 1 \\
\hline Sp.2\#6 & $60 \%$ & 1 & Sp.4\#6 & $60 \%$ & 1 & Sp.8\#6 & $60 \%$ & 1 \\
\hline Sp.2\#7 & $50 \%$ & 2 & Sp.4\#7 & $50 \%$ & 2 & Sp.8\#7 & $50 \%$ & 2 \\
\hline Sp.2\#8 & $55 \%$ & 2 & Sp.4\#8 & $55 \%$ & 2 & Sp.8\#8 & $55 \%$ & 2 \\
\hline Sp.2\#9 & $60 \%$ & 2 & Sp.4\#9 & $60 \%$ & 2 & Sp.8\#9 & $60 \%$ & 2 \\
\hline
\end{tabular}


Hand lay-up method has been used to fabricate all the specimens. Woven (Carbon and Glass) fibers are wound manually around the mold of plastic, which was coated with wax to easily remove the specimen later, and epoxy with Alumina powder resin brushed over and into the woven roving fiber in this way for (CarbonGlass)/epoxy+ $\mathrm{Al}_{2} \mathrm{O}_{3}$. After preparing all the materials, the first step in fabrication starts with cutting the woven roving fiber manually. The fiber used to fabricated the active area is mixed between the carbon fiber woven roving and glass fiber woven roving and other things is totally the same, also 27 specimens were fabricated, 9 specimens for each number of layer 2, 4 and 8 . Fibers pieces for the active area should cut and prepare before fabricating and also the mandrels should be ready, then in the fabrication of this case the fiber Glass piece must rolled at first then the Carbon fiber were rolled around the glass fiber in order to make the hybrid fiber specimens, the inactive area will be from glass fiber also, Figure 2 will show the fabrication process for hybrid/Epoxy- $\mathrm{Al}_{2} \mathrm{O}_{3}$ specimens.

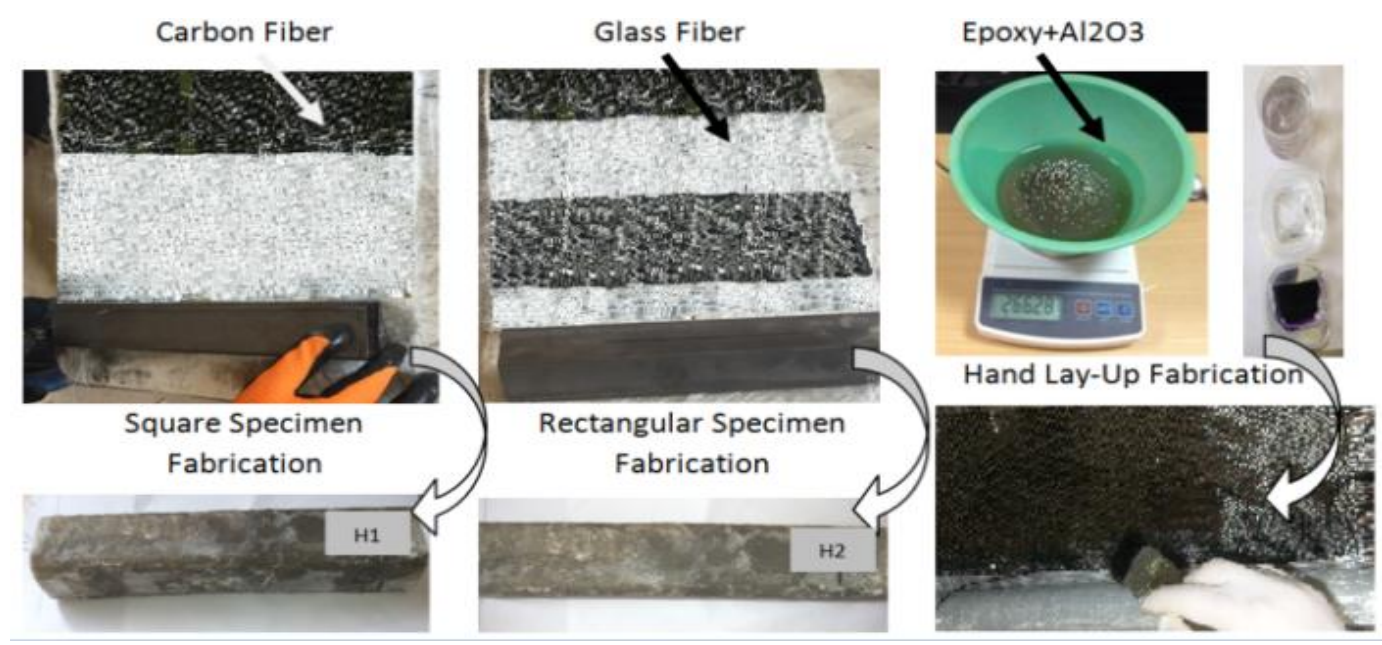

Figure 2: Two and four layers specimen fabrication of hybrid composite

The tests were conducted at room temperature between 25-28 $\mathrm{C}^{\mathrm{o}}$ and the time required for solidification of all specimens is about $72 \mathrm{~h}$ to provide optimum blend.

\subsection{Specimens Testing}

The device that is used to examine the samples is MATEST S.R.L TREVOLO 08 24048 ITALY bending device where the sample is horizontally installed, and then is lowered on a sample of bending arm commends the sample down to a case of total failure of the sample where the purpose of the experiment is to examined the maximum load under the influence of bending, bending device is shown in Figure 3 .
After conducting laboratory tests on a composite of Carbon-glass fiber / Epoxy + Alumina showed practical results of the effect of bending load on hollow columns that is made of composite material of Hybrid/Epoxy- $\mathrm{Al}_{2} \mathrm{O}_{3}$. This study has two forms through the rectangular tube selection (hollow columns) $\mathrm{a} / \mathrm{b}(\mathrm{a} / \mathrm{b}=0.5$ and 2 , square $\mathrm{a}$ $/ \mathrm{b}=1)$ with 3 types of layers of samples $(2,4$ and 8) layers. Totally more than 27 specimens were facts of this compound for both forms to take the test. All samples were tested. In this study, a statement bearing capacity of those columns resist bending applied on the central subject of the test sample.

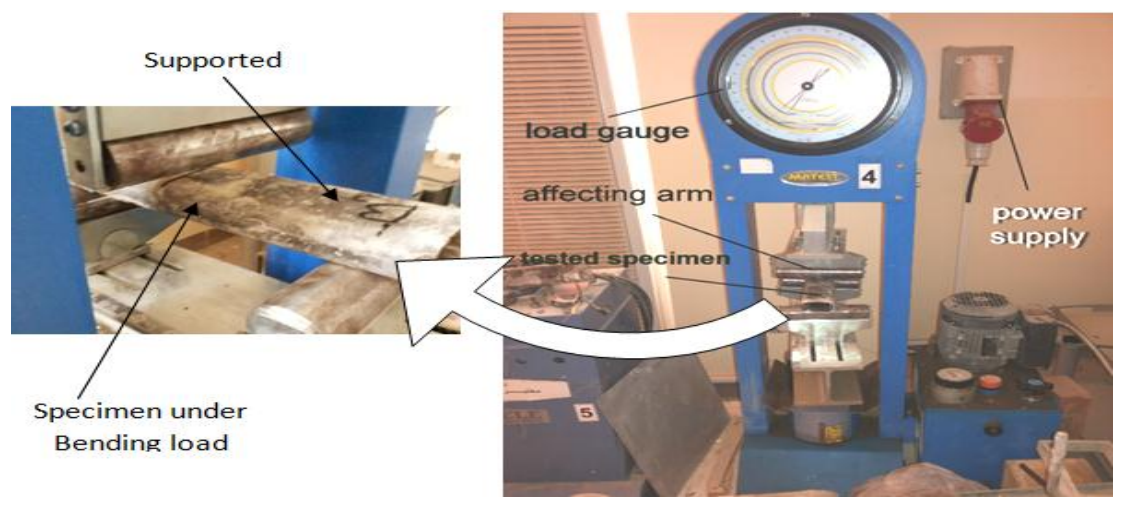

Figure 3: Matest S.R.L trevolo 0824048 italy bending test device 


\section{Autodyn Simulation}

The standard 3D AUTODYN in ANSYS 15 model was used to investigate this simulation, Lagrange code was used and created, so that cell boundaries occurred at free surfaces and material boundaries. Another point is that during calculations, the mesh would distort to match the distortion of the material, so the mesh assumed in this study was Explicit -Auto-meshing and the standard properties of Hybrid/Epoxy- $\mathrm{Al}_{2} \mathrm{O}_{3}$ composite laminated plate. The finite element mesh used for the analysis consisted of 1560
QUAD4.elements, as shown in Figure 4. The load cases considered, which were a variety of maximum stress. The 27 hybrid specimens are solved by Explicit Dynamics in AUTODYN 15 to be representative of a lateral Carbon-Glass/E$\mathrm{Al}_{2} \mathrm{O}_{3}$ with non-linear analysis of specimen dimensions (length, $\mathrm{L}=320 \mathrm{~mm}$, high, $\mathrm{a}=12.5$ $\mathrm{mm}$ and width, $\mathrm{b}=25 \mathrm{~mm}$ ) with $1.25 \mathrm{~mm}$, $2.4 \mathrm{~mm}$ and $4.7 \mathrm{~mm}$ thickness of specimen. The boundary condition of specimen is simply supported beam on both ends and the loading similar to that of the test specimens as shown in Figure 4 .
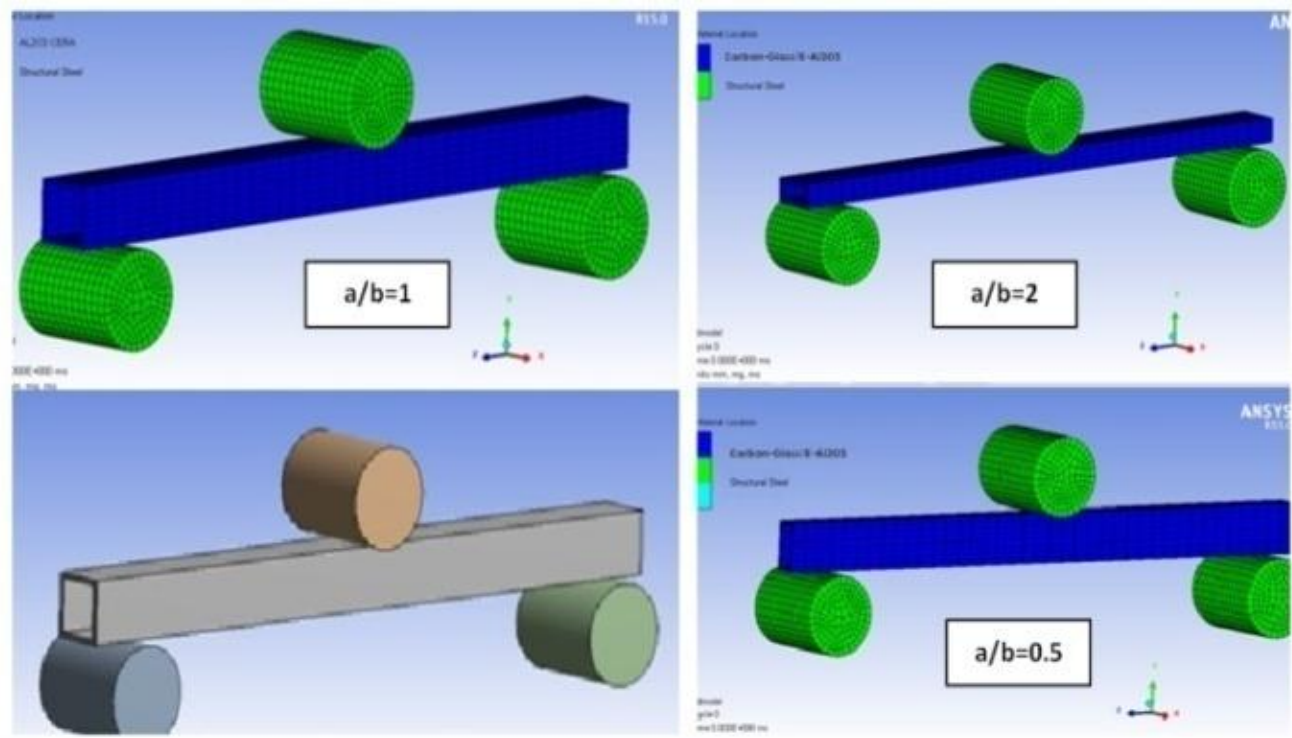

Figure 4: Autodyn V.15 - Geometry modeling for different shape of cross-sectional area of Hybrid specimens

\section{Results and Discussions}

The bending test applied for the three types of layers of composite specimen sets and the test result will be discussed below and according to maximum bending stress capacity for number of layers and by using volume fraction of composite relations and parameters will find and
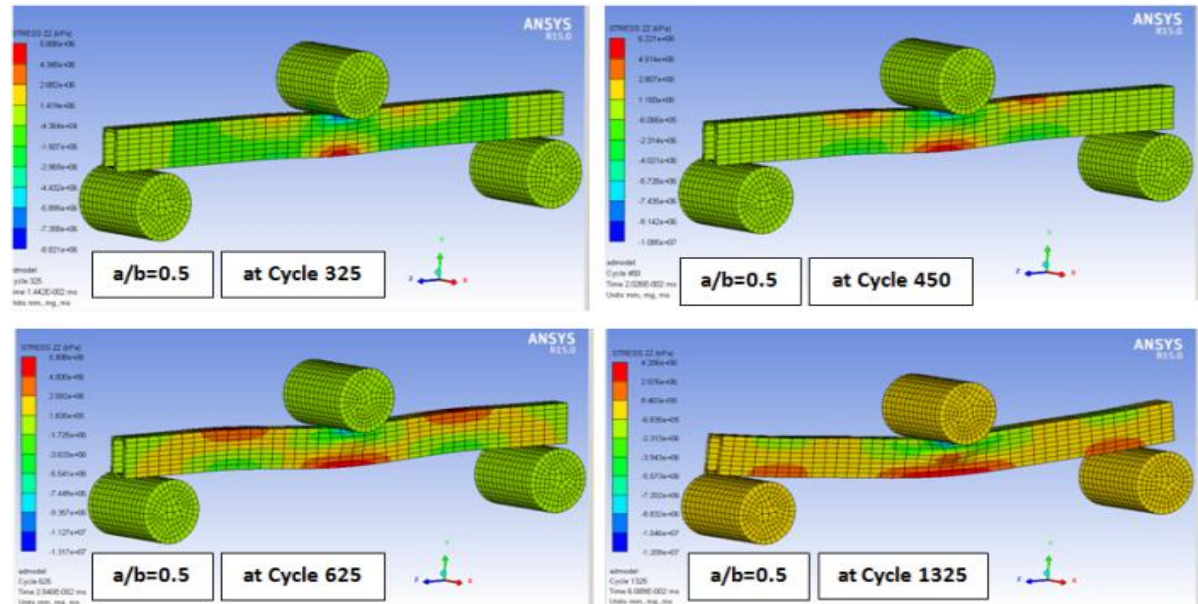

Figure 5: Deformation of Hybrid/epoxy- $\mathrm{Al}_{2} \mathrm{O}_{3}$ of rectangular cross-sectional area of specimen under test at different cycles 
A prescribed incremental bending loading is by applying loading on the mid of the specimen, while the ends are simply supported fixed.
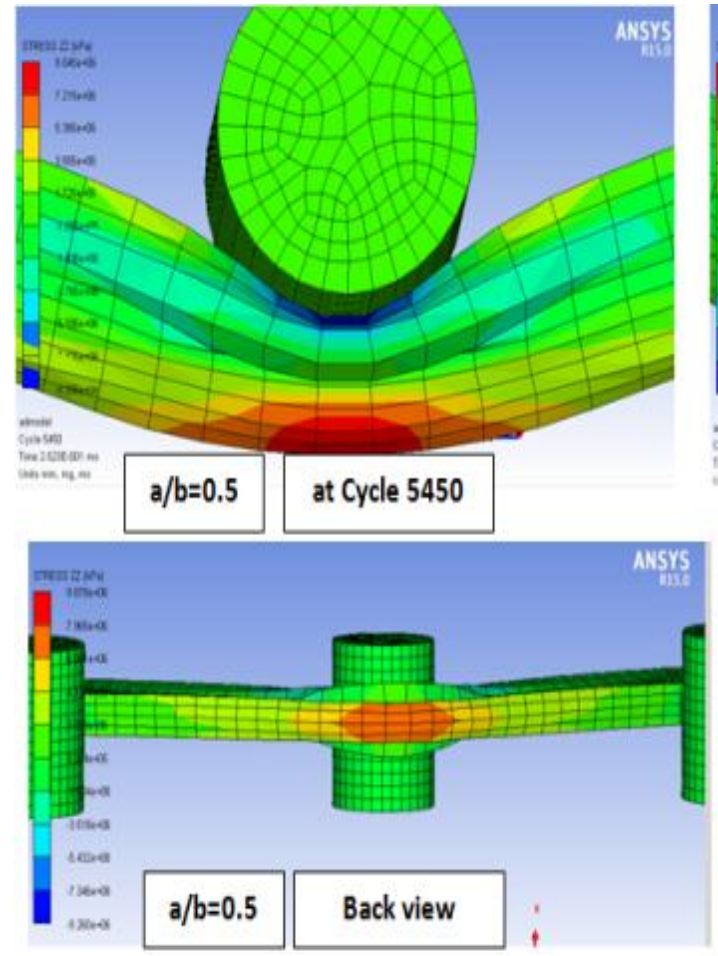

Figure 6 shows the maximum deformed state of rectangular tube of Hybrid specimen under bending load with $\mathrm{a} / \mathrm{b}=0.5$
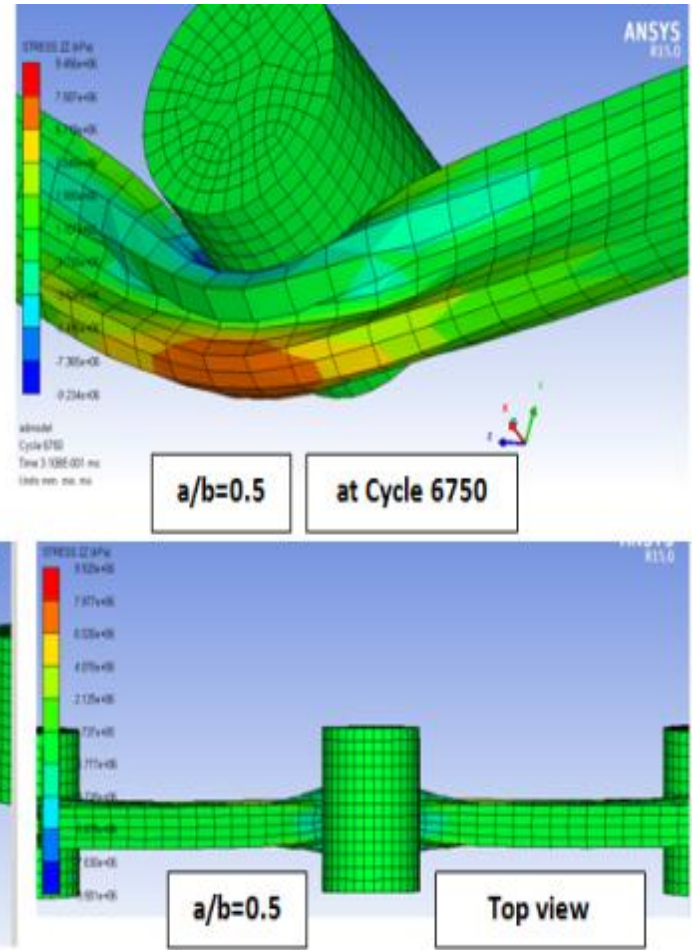

Figure 6: Maximum deformation of $\mathrm{Hybrid} / \mathrm{epoxy}-\mathrm{Al}_{2} \mathrm{O}_{3}$ of rectangular cross-sectional area of specimen under test at different cycles

Another example shows the influence of maximum stress loading on specimen was modeled as shown in Fig. 7 below of rectangular cross-sectional area with $\mathrm{a} / \mathrm{b}=2$ at different number of cycle.
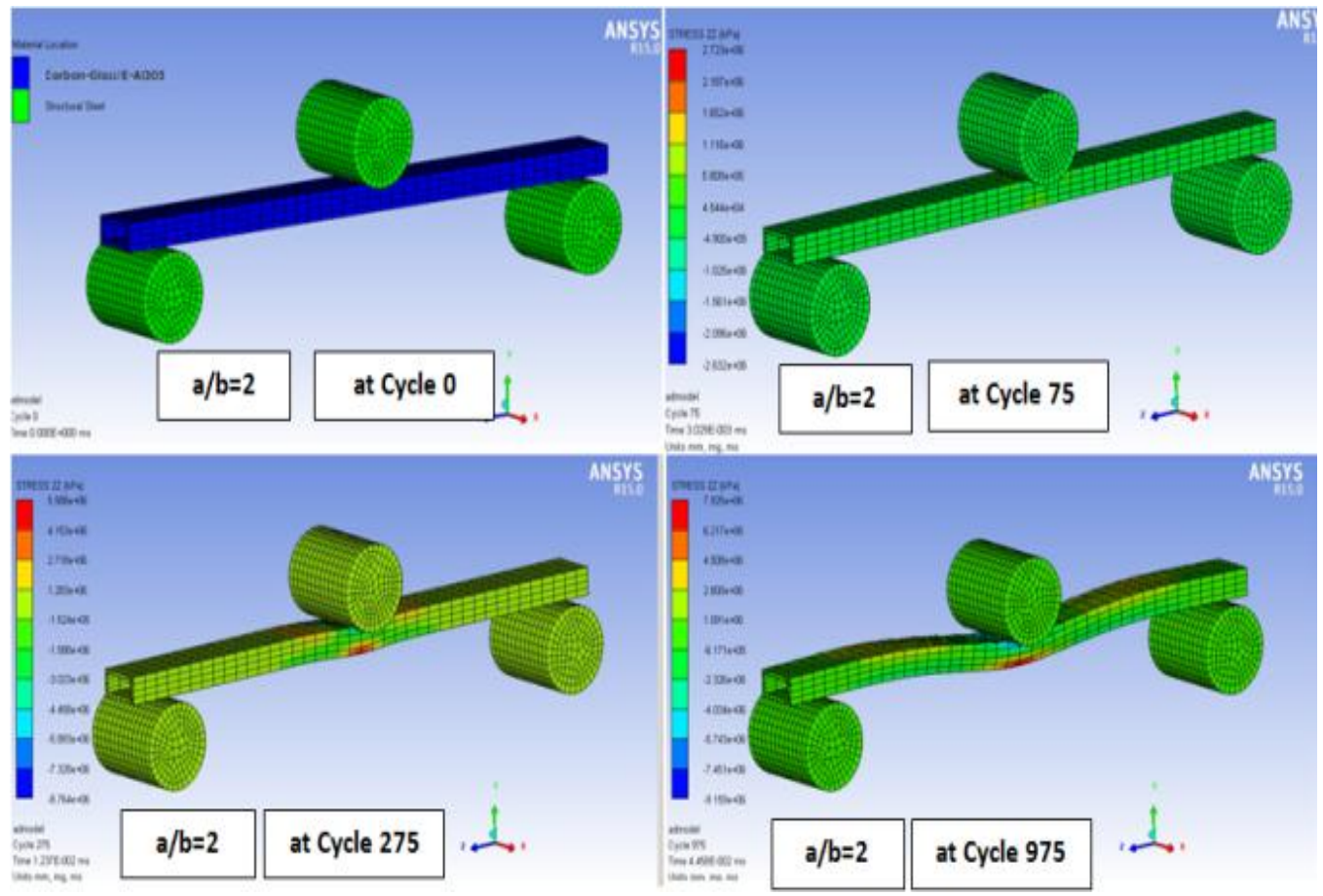

Figure 7: Deformation of $\mathrm{Hybrid} / \mathrm{epoxy}-\mathrm{Al}_{2} \mathrm{O}_{3}$ of rectangular cross-sectional area $\mathrm{a} / \mathrm{b}=2$ of specimen under test at different cycles 
The influence of maximum stress loading on specimen was showed as back view as shown in
Fig. 8 below of rectangular cross-sectional area with $\mathrm{a} / \mathrm{b}=2$ at different number of cycle.
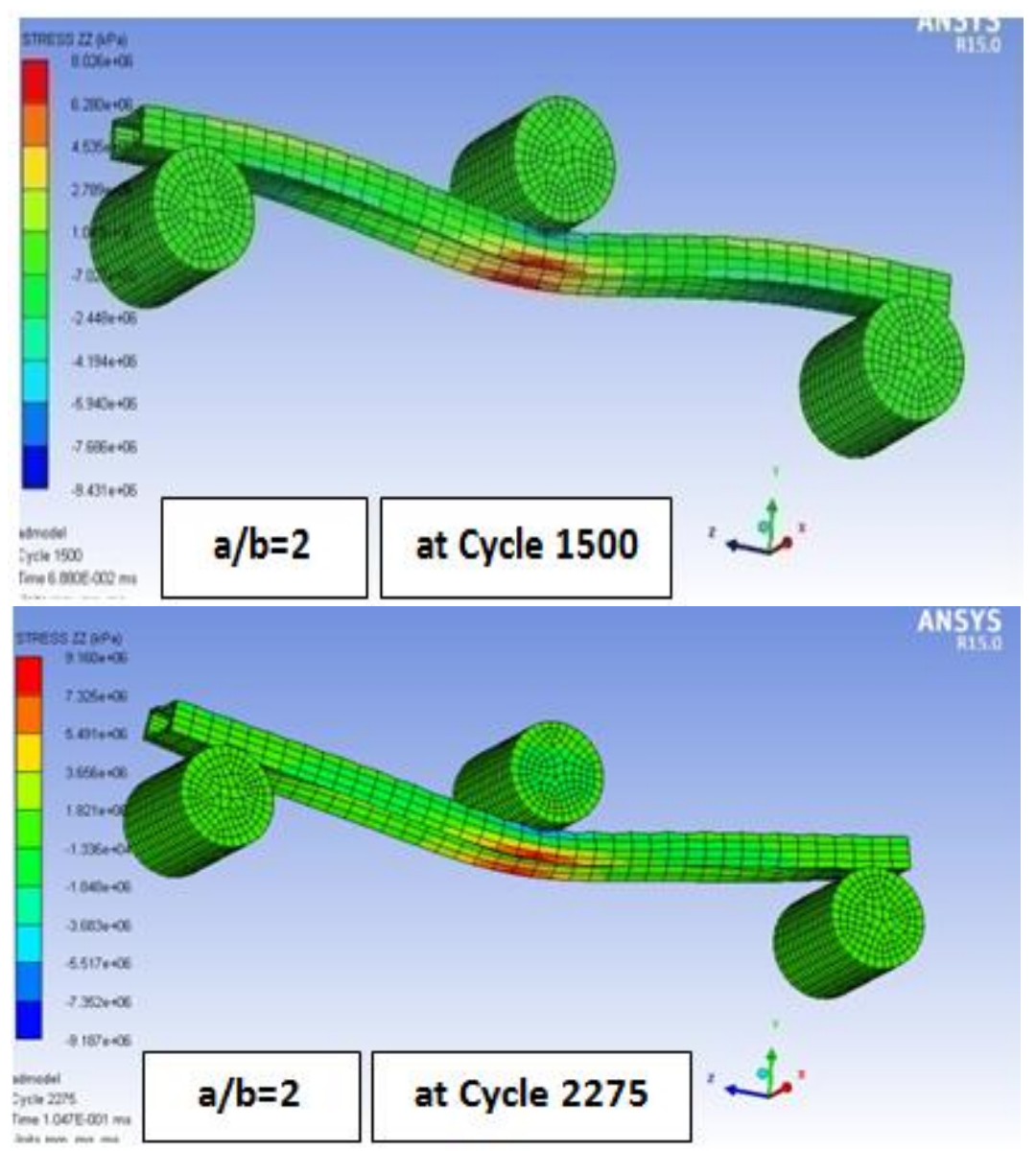

Figure 8: Back view of deformation of $\mathrm{Hybrid} / \mathrm{epoxy}-\mathrm{Al}_{2} \mathrm{O}_{3}$ of rectangular cross-sectional area $\mathrm{a} / \mathrm{b}=2 \mathrm{of}$ specimen under test at different cycle

The deformation occurred during different time and cycle of bending load variation. A different view showed in Fig. 9 below of rectangular cross-sectional area with $\mathrm{a} / \mathrm{b}=2$ at different number of cycle.
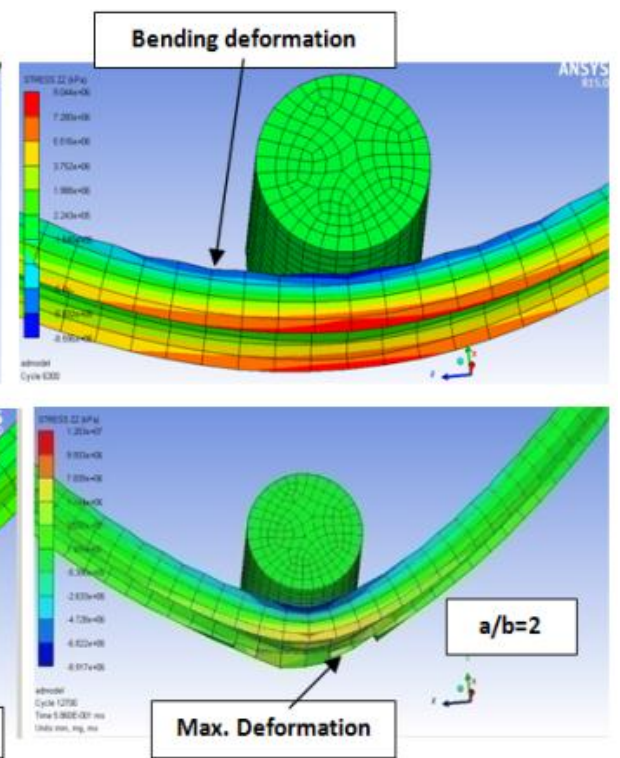

Figure 9: Stress deformation examples of specimens without cut-out at time $(0.0678 \mathrm{~ms})$ and with cut-out at time (0.2086 $\mathrm{ms})$ under tensile test 

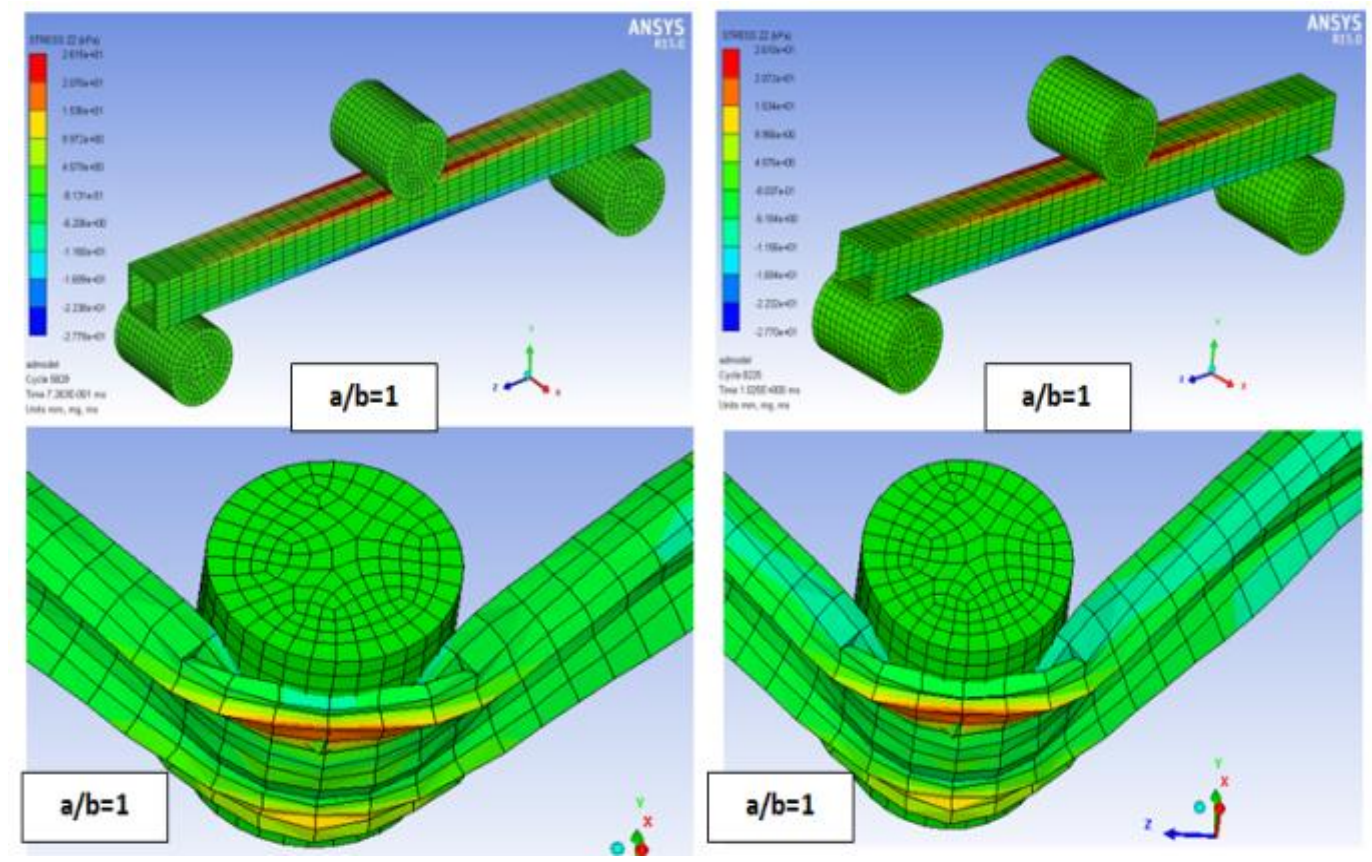

Figure 10: Back view of deformation of $\mathrm{Hybrid} / \mathrm{epoxy}-\mathrm{Al}_{2} \mathrm{O}_{3}$ of rectangular cross-sectional area $\mathrm{a} / \mathrm{b}=1$ of specimen under test at different cycle

The maximum value of the stress obtained is $443 \mathrm{MPa}$ and $469 \mathrm{MPa}$ of experimental and simulation result respectively at $55 \%$ volume fraction of 2 layers of Hybrid/Epoxy- $\mathrm{Al}_{2} \mathrm{O}_{3}$ specimen at $\mathrm{a} / \mathrm{b}=0.5$ as shown in Figure 11 , while the minimum values of stress capacity are obtained for all specimens that have $50 \%$ volume fraction with $\mathrm{a} / \mathrm{b}=2,1$ and 0.5 , but the smallest value is occurred at $a / b=2$. The difference in results due to cross-sectional area of the specimens have different shapes, hence the moment of inertia is different, this lead to maximum load capacity of bending has different value. Large different has been occurred in this figure between the simulation and experimental study for the samples made from the composite (Hybrid / Epoxy - alumna) of the two layer is caused by the high sensitivity of the impact of those materials with a low thickness to bear bending, The properties of the hybrid to the virtual library may show a difference in results because the composite is non-standard and is not in the list of materials available in the simulator designed for this purpose.
Figure 12 illustrates the variation of the maximum stress capacity of bending for all specimens with different volume fraction of 4 layers of composite materials. The maximum load capacity increased gradually from the lowest value of volume fraction in Hybrid/Epoxy- $\mathrm{Al}_{2} \mathrm{O}_{3}$ specimens until the highest value can notice in $55 \%$ volume fraction specimens then decreased gradually until reach to $60 \%$ volume fraction of specimens. The maximum value is obtained by $866 \mathrm{Mpa}$ and 846 Mpa for simulation and experimental respectively at $\mathrm{a} / \mathrm{b}=0.5$ with $55 \%$ volume fraction of specimen.

The same behavior as before that showed in Figure 12, the curves shown in Figures 13 has peak point at $55 \%$ with $\mathrm{a} / \mathrm{b}=0.5$ and minimum value at $50 \%$ volume fraction with $a / b=2$. The maximum values obtained from above Figures are $1597 \mathrm{Mpa}$ and $1557 \mathrm{MPa}$ for simulation and experimental results respectively of 8 layers hybrid/Epoxy- $\mathrm{Al}_{2} \mathrm{O}_{3}$. 


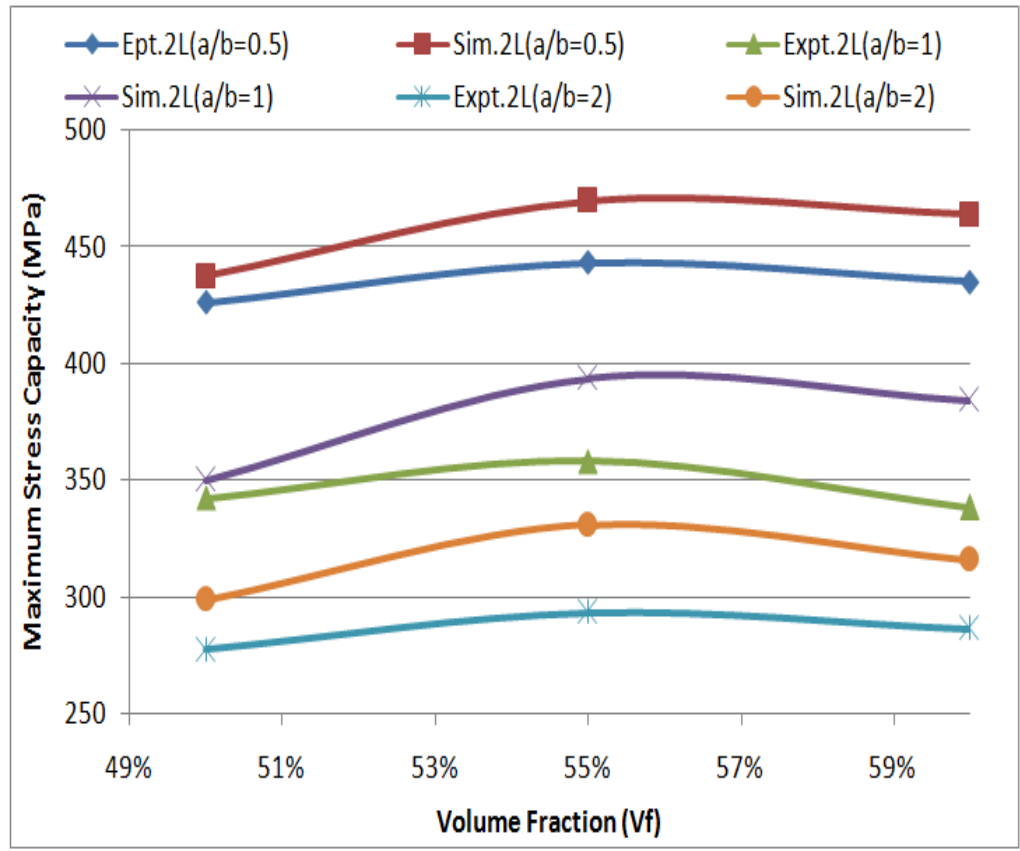

Figure 11: Volume fraction vs maximum stress capacity of 2 layers of Hybrid/Epoxy+ $\mathrm{Al}_{2} \mathrm{O}_{3}$

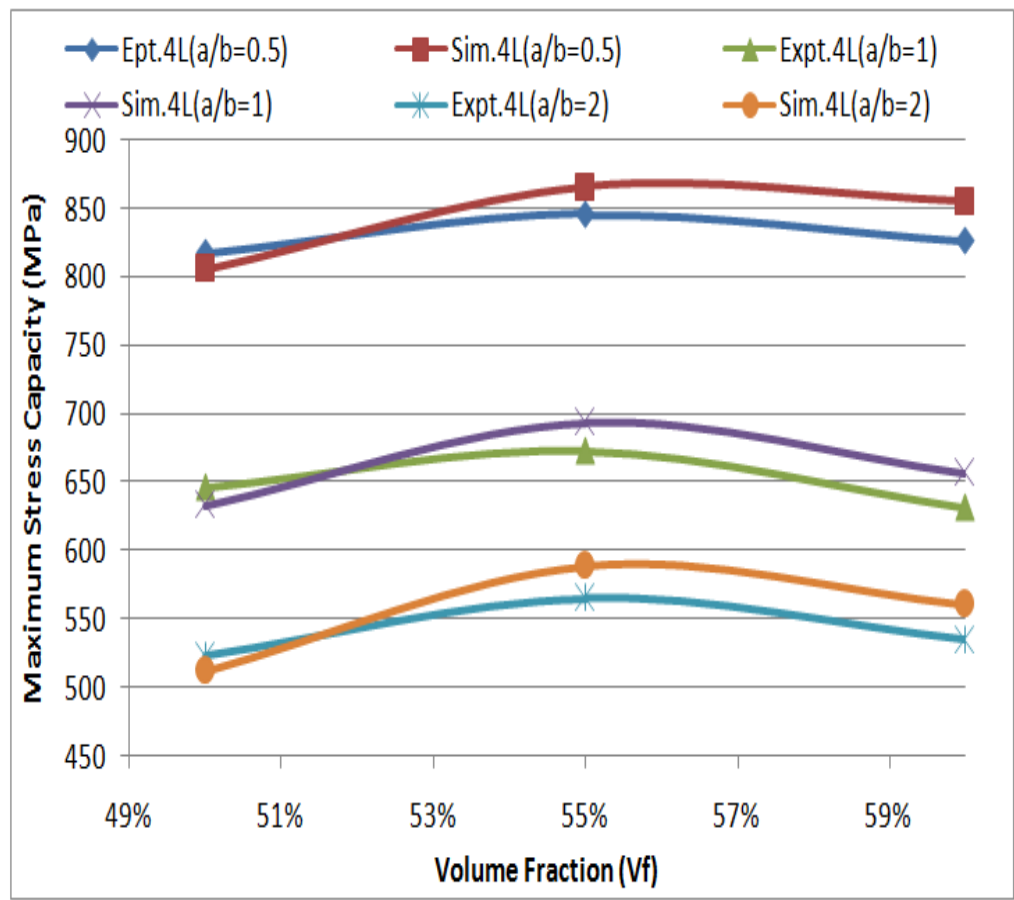

Figure 12: Volume fraction vs maximum stress capacity of 4 layers of Hybrid/Epoxy+ $\mathrm{Al}_{2} \mathrm{O}_{3}$

The same behavior as before that showed in Figure 12, the curves shown in Figures 13 has peak point at $55 \%$ with $\mathrm{a} / \mathrm{b}=0.5$ and minimum value at $50 \%$ volume fraction with $\mathrm{a} / \mathrm{b}=2$. The maximum values obtained from above Figures are $1597 \mathrm{Mpa}$ and $1557 \mathrm{MPa}$ for simulation and experimental results respectively of 8 layers hybrid/Epoxy- $\mathrm{Al}_{2} \mathrm{O}_{3}$. 


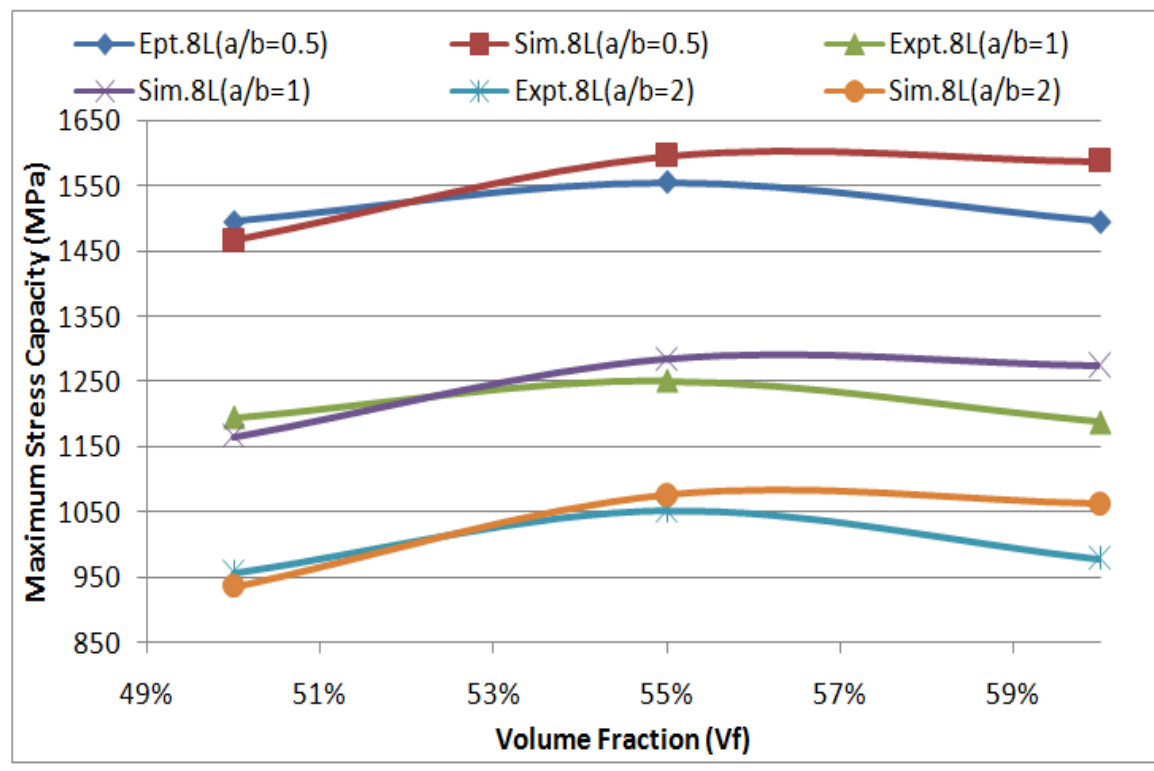

Figure 13: Volume fraction vs maximum stress capacity of 8 layers of Hybrid/Epoxy $+\mathrm{Al}_{2} \mathrm{O}_{3}$

The maximum load that the $55 \%$ volume fraction of composite specimens can carry it always more than other types of volume fractions $(50 \%$ and $60 \%)$ of specimens and the maximum bending load it directly proportional to the number of layers. Also the variation of thickness to high ratio $(a / b)$ of the specimen also effects on the values of maximum stress capacity. The 8 layers (8L) of specimens always can carry the highest load capacity comparing with other specimens that made from two layers (2L) and four layers (4L). Experimental and simulation differences have listed in Table 3 . with maximum error $11.98 \%, 7.93,4.67 \%$ at specimen Sp.2\#6, Sp.8\#9 and Sp.4\#9 for specimens that have 2,8 and 4 layers respectively. Also the Increasing ratio of stress capacity for specimens have 4 to 2 layers (4/2) and 8 to $4(8 / 4)$ for experimental results have maximum value with increasing by $48.19 \%$ and $46.84 \%$ at (Sp.4\#8/Sp.2\#4) and (Sp.8\#6/Sp.4\#6) respectively.

The difference in the results obtained from the output samples are subject to the tests form by applying vertical force on the samples where it is known that the section of the form changes the moment of inertia and consequently change the amount of the maximum load of samples pregnant when exposed to external stresses.

Table 3 Increasing ratio of load capacity with layers ratio.

\begin{tabular}{|c|c|c|c|c|c|c|c|c|c|}
\hline $\begin{array}{c}\text { Volume } \\
\text { fraction } \\
V_{\mathrm{f}}\end{array}$ & $\begin{array}{c}\text { Width/ } \\
\text { High } \\
\text { Ratio } \\
\text { (a/b) }\end{array}$ & $\begin{array}{c}\text { Specimen } \\
\text { No. } \\
\text { 2Layers }\end{array}$ & $\begin{array}{c}\text { Error } \\
\% \\
\text { Expt. } \\
\text { Sim. }\end{array}$ & $\begin{array}{c}\text { Specimen } \\
\text { No. } \\
\text { 4Layers }\end{array}$ & $\begin{array}{c}\text { Error } \\
\% \\
\text { Expt. } \\
\text { Sim. }\end{array}$ & $\begin{array}{l}\text { Increasing } \\
\text { ratio of } \\
\text { stress } \\
\text { capacity } \\
4 / 2 \text { Expt }\end{array}$ & $\begin{array}{c}\text { Specimen } \\
\text { No. }\end{array}$ & $\begin{array}{c}\text { Error } \\
\% \\
\text { Expt. } \\
\text { Sim. }\end{array}$ & $\begin{array}{l}\text { Increasing } \\
\text { ratio of } \\
\text { stress } \\
\text { capacity } \\
8 / 4 \text { Expt }\end{array}$ \\
\hline $50 \%$ & 0.5 & Sp.2\#1 & 2.56 & Sp.4\#1 & -1.48 & 47.92 & Sp.8\#1 & -2.03 & 45.36 \\
\hline $55 \%$ & 0.5 & Sp.2\#2 & 5.64 & Sp.4\#2 & 2.29 & 47.64 & Sp.8\#2 & 2.51 & 45.65 \\
\hline $60 \%$ & 0.5 & Sp.2\#3 & 6.21 & Sp.4\#3 & 3.33 & 47.37 & Sp.8\#3 & 5.85 & 44.75 \\
\hline $50 \%$ & 1 & Sp.2\#4 & 2.23 & Sp.4\#4 & -2.11 & 47.09 & Sp.8\#4 & -2.56 & 45.95 \\
\hline $55 \%$ & 1 & Sp.2\#5 & 9.02 & Sp.4\#5 & 3.02 & 46.81 & Sp.8\#5 & 2.58 & 46.24 \\
\hline $60 \%$ & 1 & Sp.2\#6 & 11.98 & Sp.4\#6 & 3.80 & 46.52 & Sp.8\#6 & 6.75 & 46.84 \\
\hline $50 \%$ & 2 & Sp.2\#7 & 7.20 & Sp.4\#7 & -2.25 & 47.09 & Sp.8\#7 & -2.36 & 45.36 \\
\hline $55 \%$ & 2 & Sp.2\#8 & 11.43 & Sp.4\#8 & 3.99 & 48.19 & Sp.8\#8 & 2.23 & 46.30 \\
\hline $60 \%$ & 2 & Sp.2\#9 & 9.38 & Sp.4\#9 & 4.67 & 46.52 & Sp.8\#9 & 7.93 & 45.36 \\
\hline
\end{tabular}

Practical results have shown from Table 3, the increase by bending pregnancy with the number of layers for each sample where the results showed that the maximum increasing was by $48.3 \%$ of a class of samples (4/2) and $50 \%$ for samples with a layer (8/4). The difference in the results obtained from the output samples are subject to the tests form and way to shed the vertical force on the samples where it is known that the section of the form changes the moment 
of inertia and consequently change the amount of the maximum load of samples pregnant when exposed to external stresses. For the theoretical side, the same behavior in the practical side in the form of curves with an acceptable error rate where the properties of the materials used in this research of multi layers of hybrid / Epoxy- $\mathrm{Al}_{2} \mathrm{O}_{3}$ with different volume fraction as a factor also showed that at $55 \%$. This difference is the result of the fact that known mechanical properties (tensile, compression, strength) are strongest at this volume fraction ratio and gradually decrease by increasing or decreasing by $55 \%$.

In general, a composite would consist of a reinforcing fiber which is the strongest and stiffest component, embedded in a continuous matrix. The main functions of the matrix are to transmit externally applied loads to the fiber and to protect the latter from external mechanical damage. Fiber volume fraction is one of the most important factors controlling the strength, stiffness and many other mechanical properties of the composites.

\section{Conclusion}

It was found:-

1- The maximum load of specimens increased with increasing number of layers from $2 \mathrm{~L}$ to $8 \mathrm{~L}$.

2- The results also identified that the maximum load capacity by $55 \%$ volume fraction and $\mathrm{a} / \mathrm{b}=0.5$ of all composite specimens was highest from the others types of $(50 \%$ and $60 \%)$ volume fractions and $(\mathrm{a} / \mathrm{b}=1$ and $\mathrm{a} / \mathrm{b}=2)$.

3- The Increasing ratio of stress capacity for specimens have 4 to 2 layers $(4 / 2)$ and 8 to $4(8 / 4)$ for experimental results have maximum value with increasing by $48.19 \%$ and $46.84 \%$ at (Sp.4\#8/Sp.2\#4) and (Sp.8\#6/Sp.4\#6) respectively.

4- The maximum differences of experimental and simulation errors were obtained by $11.98 \%, 7.93,4.67 \%$ at specimen Sp.2\#6, Sp.8\#9 and Sp.4\#9 for specimens that have 2, 8 and 4 layers respectively.

5- The Increasing ratio of stress capacity for specimens have 4 to 2 layers $(4 / 2)$ and 8 to 4 (8/4) for experimental results have maximum value with increasing by $48.19 \%$ and $46.84 \%$ at (Sp.4\#8/Sp.2\#4) and (Sp.8\#6/Sp.4\#6) respectively.

\section{Acknowledgements:}

The authors wish to thank Department of Mechanical Engineering, University of Kirkuk for providing the full requirements of the experimental work in this research.

\section{References}

[1]. popular science and technology series, composite materials ,DESIDOC, ministry of defense, metcalfoe house ,(1990).

[2]. Bryan Harris. engineering composite materials, the institute of materials, London, (1999).

[3]. Raif Sakinand IrfanAY. statistical analysis of bending fatigue life data using weibull distribution in glass- fiber reinforced polyester composites, materials and design, 29, issu.6, (2008), p.p 170-1181.

[4]. Limin Bao , Natsuki Kamada , Danna Qian , Tomohiro Shirayi, Sotomi Gotou \& Kiyoshi Kemmochi .Improvement of the Bending Characteristics of Thin FRP Cylinders by Imitating Nodes of Bamboo. Advanced Composite Materials., 19, 2 (2010), p.157p.170.

[5]. Palmer SO, Nettles AT and Poe Jr, CC.An experimental study of a stitched composite with a notch subjected to combined bending and tension loading. NASA Report No. NASA/TM-1999-209511, National Technical Information Service, (1999).

[6]. Wisnom MR. The relationship between tensile and flexural strength of unidirectional composites. J Comp Mater, 26, (1992), p.1173-p.1180..

[7]. Khashaba UA. On the mechanical behavior of [0/_45/90]s woven composites subjected to combined bending and tension loading, In: Proceedings of the 4th International Engineering Conference, Mansoure University, Egypt, 1, (2004), p.527-p.539.

[8]. Khashaba UA and Seif MA. Effect of different loading conditions on the mechanical behavior of $[0 / 445 / 90] \mathrm{s}$ woven composites. J Compos Struct, 74, (2006), $440-448$.

[9]. Liu XY and Yu WD.Bending fatigue properties of single aramid fibers. Chem Fibers Int, 54(3), (2004), 173-175.

[10]. $\mathrm{Gu} \mathrm{BH}$. Bending fatigue properties of single wool fibers. J Text Res, 14(4), (1992), 157-159.

[11]. Burgoyne CJ, Hobbs RE and Strzemiecki J.Tension bending and sheave bending fatigue of parallel lay aramid ropes. In Proceedings of 8th international conference on offshore mechanics and arctic engineering. The Hague, Netherlands, March, (1989) p.691-692. 
[12]. Mower TM. Sheave-bending and tensile fatigue of aramid-fiber strength members for

[13]. Kohji M, Yoshihiro M and Kenjiro K.The influence of vacuum on fracture and fatigue behavior in a single aramid fiber. Int $\mathrm{J}$ Fatigue, 22, (2000), 757-765.

[14]. Kollar LP and Springer GS. Mechanics of composite structures. Cambridge, UK: Cambridge University Press, 2003.

[15]. Barbero EJ. Introduction to composite materials design. Boca Raton, FL: CRC Press, 2010.

[16]. Agarwal BD, Broutman LJ and Chandrashekhara K.. Analysis and performance of fiber composites. Hoboken, New Jersey: John Wiley and Sons Inc.2006.

[17]. Mallick PK. Fiber reinforced composites: Materials, manufacturing and design. Boca Raton, FL: CRC Press, 2008.

[18]. Kaw AK.. Mechanics of composite materials. Boca Raton, FL: CRC Press, 2006.

[19]. Bank LC. Composites for construction. Hoboken, New Jersey: John Wiley and Sons Inc, 2006.

[20]. Vinson JR and Sierakowski RL. The behavior of structures composed of composite materials. Dordrecht, The Netherlands: Springer Science \& Business Media, 2008.

[21]. Muhammad AM Qureshi, Hota V GangaRao, Nasir Hayat and Praveen Majjigapu. Response of closed Glass Fiber Reinforced Polymer sections under combined bending and torsion. Journal of Composite Materials, 51(2), (2017), p.241-p.260

[22]. Phan, N.D. and Reddy, J.N. Analyses of Laminated Composite Plates using a Higherorder Deformation Theory, Int. J. Num. Meth. Engg., 21(12), (1985), p.2201p.2219.

[23]. IdIbi, A., Karama, M. and Touratier, M. Comparison of Various Laminated Plate, 1997.

[24]. Karama, M., Afaq, K.S. and Mistou, S. Mechanical Behavior of Laminated Composite Beam by New Multi-layered Laminated Composite Structures Model with Transverse Shear Stress Continuity, Int. J. Solids Struct., 40(6), (2003), p.1525-p.1546, communications cables. Int $\mathrm{J}$ Fatigue, 22, (2000),

121-135.

[25]. Librescu L and Song O. Thin-walled composite beams. Dordrecht, The Netherlands: Springer, 2006.

[26]. Salim HA and Davalos JF. Torsion of open and closed thin-walled laminated composite sections. J Compos Mater, 39, (2005), p.497p.524.

[27]. Roberts TM and Al-Ubaidi H. Flexural and torsional properties of pultruded fiber reinforced plastic I-profiles. J Compos Construct, 6, (2002), 28-34,

[28]. Lekhnitski SG. Anisotropic plates. Gordon and Breach, 1968.

[29]. Whitney JM. Structural analysis of laminated anisotropic plates. Technomic Publishing Company, 1987.

[30]. ASCE LRFD manual for pultruded Fiber Reinforced Polymer (FRP) structures (Draft). ASCE-ACMA Joint Publication, Draft Version,

[31]. Eurocode No. 3. Design of steel structures Part I - General rules and rules for buildings (Draft). Commission of the European Communities, 1988.

[32]. Creative Pultrusions Inc. The Pultex pultrusion design manual. Vol. 4, Revision 6. Available at: http://www.readbag. com/creativepultrusions-litlibrarydesignmanualdmv4r6, 2004.

[33]. F.C.Campbell., structural composite materials , ASM international, 2010.

[34]. Bhas Kark., static analyses of portal axel outpot shaft using composite materials , international journal of research in engineering and technology, e issn:23191163/p issn: 2321-7308, vol.03, special issue:03, may, india, (2014).

[35]. Niharika Mohanta and S.K.Acharya. “ investigation of mechanical properties of luffa cylindrical fiber reinforced epoxy hybrid composite", international journal of engineering science and technology, 7(1), (2015), pp1-10.

[36]. Hani Aziz., Mechanical properties of composite materials using natural rubber with epoxy resin, engineering and technology, 26(2),

(2008). 